Meta

Journal des traducteurs

Translators' Journal

\title{
An Overview of the Korean Translation Market
}

\section{Jungwha Choi et Hyang-Ok Lim}

Volume 45, numéro 2, juin 2000

URI : https://id.erudit.org/iderudit/002235ar

DOI : https://doi.org/10.7202/002235ar

Aller au sommaire du numéro

\section{Éditeur(s)}

Les Presses de l'Université de Montréal

ISSN

0026-0452 (imprimé)

1492-1421 (numérique)

Découvrir la revue

Citer cet article

Choi, J. \& Lim, H.-O. (2000). An Overview of the Korean Translation Market. Meta, 45(2), 383-392. https://doi.org/10.7202/002235ar

\section{Résumé de l'article}

Cet article a pour objectif de passer en revue le marché coréen de la traduction. La première partie étudie la traduction à la pige en se concentrant sur la Korean Society of Conference Interpretation.On traite des conditions de travail, des tarifs de traduction en vigueur et des problèmes qui en découlent. On explique également ce phénomène unique à la Corée qu'est la « draft translation ». La deuxième partie examine le marché des traducteurs salariés. La dernière partie, quant à elle, divise le marché en catégories en s'appuyant sur les divers types de textes. On ne tient pas compte des textes littéraires, car les cabinets ont principalement à travailler sur des textes techniques et le contrôle de la qualité est relativement sévère. Un autre type de texte pour lequel il y a un marché est le matériel audio-visuel. Finalement, sont émises des recommandations sur la façon de corriger la situation dans quelques domaines.
Ce document est protégé par la loi sur le droit d'auteur. L'utilisation des services d'Érudit (y compris la reproduction) est assujettie à sa politique d'utilisation que vous pouvez consulter en ligne.

https://apropos.erudit.org/fr/usagers/politique-dutilisation/ 


\section{An Overview of the Korean Translation Market}

\section{RÉSUMÉ}

Cet article a pour objectif de passer en revue le marché coréen de la traduction. La première partie étudie la traduction à la pige en se concentrant sur la Korean Society of Conference Interpretation. On traite des conditions de travail, des tarifs de traduction en vigueur et des problèmes qui en découlent. On explique également ce phénomène unique à la Corée qu'est la «draft translation». La deuxième partie examine le marché des traducteurs salariés. La dernière partie, quant à elle, divise le marché en catégories en s'appuyant sur les divers types de textes. On ne tient pas compte des textes littéraires, car les cabinets ont principalement à travailler sur des textes techniques et le contrôle de la qualité est relativement sévère. Un autre type de texte pour lequel il y a un marché est le matériel audio-visuel. Finalement, sont émises des recommandations sur la façon de corriger la situation dans quelques domaines.

\section{ABSTRACT}

The purpose of this article is to review the Korean translation market. The first part looks at independent translation focusing on the Korean Society of Conference Interpretation. Working conditions, translation rates and the problems involved are discussed. A unique phenomenon in Korea, the so-called "draft translation," is explained. The second part looks at the market of salaried translators or in-house translators. The last part categorizes the market according to the different type of texts. Literary texts are not included; agencies deal mainly in technical texts and quality control is relatively strict. Another type of text for which there is a market is audiovisual material. Suggestions as to how to rectify the situation in a few areas.

\section{MOTS-CLÉS/KEYWORDS}

Korean translation market, translation texts, status of translators, translation fees, draft translation 
According to a newspaper article published in early 1997, the translation market in Korea is about US $\$ 8$ million and recent signs indicate that it is growing rapidly. This is an estimate which can be adjusted depending on how the translation market is defined. The market can be divided between independent (or freelance) translators and salaried translators or according to types of texts which vary from technical texts, audiovisual texts, administrative documents to literary works. This paper will define the translation market according to the status of translators in Korea, salaried translators and the market according to types of texts.

\section{THE STATUS OF KOREAN TRANSLATORS}

1. Independent Translation Market and Translation Fees

a) Korean Society of Conference Interpretation (KSCI)

Members of institutes or associations retain the status of "researcher" and receive translation work from the relevant institutions. The most representative of such institutions is the KSCI, a society that combines research and practice in interpretation and translation. Members of the KSCI must be graduates of schools of interpretation and translation who receive recommendations from professors and meet the qualifications of the KSCI. The KSCI provides services mainly in eight foreign languages (English, French, Spanish, German, Russian, Japanese, Chinese, and Arabic), but when the need arises can make arrangements for other languages as well.

The KSCI is able to guarantee the quality of the translators by having strict membership qualifications which are coupled with internal and external supervisory controls to ensure that the standards are maintained. Upon entry, the members are given a code of ethics which must be adhered to as long as they are members. The membership consists of 50 full and 250 associate members for a total of 300 members. They are all encouraged to participate in an annual seminar where basic research can be discussed in an open forum. This is in line with the KSCI's continued efforts to balance practice and theory. In addition to the work they receive from the KSCI, established translators very often have their own private clientele.

\section{b) Korean Translators Association}

Besides the KSCI, there are several other associations such as the Korean Translators Association. According to their literature, they have full members, associate members, honorary members, special members and group members. The full members are

1. instructors who teach foreign languages (starting from assistant professors)

2. those who have published at least two books

3. instructors who have taught foreign languages for at least five years

4. instructors who have taught at foreign language institutes for more than five years or have worked in the media

5. those who have lived in a foreign country more than 10 years and are able to translate

6. foreigners who live in Korea and are recognized by the Association's Council.

According to the Association, a "proofreading committee" consisting of a senior member and a foreigner cross-check the translation to verify that there are no mistakes. There are 400 full members, of whom 172 are English translators.

Despite the fact that this Association purports to be an association of translators, it does not appear to take particular interest in elevating the status of those who have completed translation studies. Instructors who have "taught foreign languages" can become full members and there is no special consideration given to the professionalism of translation studies. Despite the fact that the number of competent researchers in the field of translation studies is increasing, there seems to be a lack of will or interest to systematically incorporate qualified professionals. But more importantly, it seems odd that members of such an association are mainly language teachers. While it is understandable that laypersons have difficulty making the distinction between language teachers and professional translators, to have the association perpetuate the myth of such an equivalence is unconscionable. The fundamental concept that language is simply a tool used by translators does not seem to be understood by the association.

The number of independent translators in Korea has not been verified. However, given the recent "translator boom," unemployment among college graduates, housewives looking for parttime jobs, early retirees and other social phenomena, there are an increasing number of people who describe themselves as "translators" and a conservative estimate puts the number at about ten thousand. A pitfall is that they work without having been screened for any special qualifications. The precept that anybody who can read a little in a foreign language can become a translator is still prevalent in the market. Among self-proclaimed "freelance translators," there are many who are under-qualified but still manage to find work. Among those who translate videos, either as a part-time job or as a hobby, there are many who have a mini- 
mal understanding of foreign culture or lack the necessary fluency in Korean, which leads to incorrect or inadequate translations (Hankuk Ilbo, June 9, 1995).

Most freelance translators find work through agencies or acquaintances. Lacking the financial resources to employ professional translators, small companies ask around and if there is anybody who speaks a foreign language, give the translation work to them, usually demanding that the work be done quickly. Due to a lack of understanding about translation in general, the end-result is usually a translation of low quality. There are still many who perceive translation as a side-job and not a fullfledged profession, and as an easy way for highschool graduates to earn some pocket money.

Fortunately, among independent translators, there are those who, having translated for a long time, have gained a reputation and are able to pick and choose jobs. There are not many of them and most work in the publishing field, translating best sellers. Some have graduated from the Graduate School of Interpretation and Translation (GSIT) affiliated with the Hankuk University of Foreign Studies or other similar professional schools, and after undergoing arduous training, their skills are recognized by the market. In addition, there are others who have not received any formal training as such, but thanks to their foreign language skills, understanding of foreign cultures and ease with the Korean language are able to work competently as translators.

\section{c) Translation fees for Independent Translators}

The translation fees currently accepted by the market can be divided into the public and private sector fees. Each year the government, through the Office of Supply, posts guidelines for translation fees, while the translation fees in the private sector can be divided into the fees for audiovisual material, translation in publishing and the "pure" independent translation fee. The fees for the latter category basically follow the guidelines of the KSCI, which are adjusted each year in accordance with consumer prices.

The Korean Administrative Society very simply states that translation fees for a text from Korean into a foreign language will be triple the fee for a foreign language text into Korean, while the fees for administrative documents from a foreign language into Korean will be determined according to the government budget for the given year. Consequently, the guidelines are very vague and can fluctuate greatly depending on the government budget. The only "standard," per se, is that the fee for a text translated into a foreign language will be triple that for a text translated into Korean.

Translation fees for audiovisual material vary according to the customer. The largest customers are the networks which pay according to their budget, but fall short of the rates determined by the KSCI The fees are usually set according to the length of a video tape, but at times, the networks prefer to have the translator on-site, working on the material at the network. Translators can become members of the Screenwriters Association by having more than three years experience translating audiovisual material or by translating more than 30 videos. According to an article which appeared on December 17, 1997 in the Chosun Daily, a leading newspaper, to become a professional audiovisual translator, one must complete a translation training program which usually lasts six months. After completing the training program, one becomes an employee of the network and translates cable TV programs or video material. Currently, about 10-20 translators work full-time at the public networks.

Rates for works to be published are divided into two categories. Medium to small-sized companies pay according to the number of pages translated while larger publishing firms give a percentage of the book price. The rates given by medium to small-sized companies are far below the going market rate for technical translations, which can explain the mediocre quality of the translation churned out by these publishing firms. Again, experienced and reputable translators sign contracts to receive a percentage of the book price and therefore are in a better position financially, but they are in the minority.

To understand how the fees are calculated, let's take a look at Company 'M.' Before the concept of signed copyright agreements was introduced, a fee of $10 \%$ of the book sales price was paid as the translation fee. Today, the going rate is $5-7 \%$. Since the usual rate for royalties of foreign books is about $6-7 \%$, translators are usually paid $5-7 \%$.

Translators who work for publishing companies such as ' $M$ ' are the lucky ones. But such companies usually already have a pool of translators or they ask for translations from established translators, making it difficult for novice translators to penetrate the market.

\section{d) Problems with the Translation Fees}

(i) Low prices

The current translation fees on the Korean market are, in general, too low. A rough estimate calculated based on an 8-hour work day would set the average monthly income of a translator at about US $\$ 1,600$. However, this is the case for a translator who has an established client base. For a novice 
translator, it is difficult to even talk about an average monthly income because work is very irregular. It takes resilience for even a talented translator to invest the time needed to earn a reputation and build a client base. One can only guess at the number of discouraged novice translators who opted for other professions.

A lot of preparatory work involving reading related books and preparing terminology, goes into a translation. Therefore, translators do not simply sit and translate all week long. However, because of low translation fees, translators must, at times, forfeit the preparatory stage and tackle the translation, or spend time looking for work, knowing full well that this might result in a translation of lesser quality.

Most translators aspire to become professionals in the hope that it will be a creative job with a certain amount of freedom. However, without the guarantee of a minimum income, it is difficult to continue to maintain high expectations and pride in the profession.

In order to overcome the problem of low translation fees, a two-pronged approach, both from the government and the private sector, must be taken. First the government must recognize that translation is a bona fide profession by hiring civil servants specifically for such jobs. There are several government agencies that hire people who can interpret and translate on a contractual basis. Just recently, for example, a government agency hired a graduate to interpret for senior officials and translate administrative documents when there was no interpreting to do. However, because the government did not recognize such work, a small portion of the department budget was earmarked for this interpreter/translator and since there was not enough to give her a lunch allowance, the staff in the department took turns buying her lunch. Since she was a temporary worker, her position was not officially recognized. Another frustrating turn of events was that when she attempted to go to the U.S. for work, she could not get a visa from the U.S. Embassy, because she could not obtain a certificate of employment based on her uncertain status.

Fortunately, the situation has improved considerably and the need for such translators/interpreters has been recognized by government agencies who hire them on a temporary basis. Almost all government ministries and agencies have at least one translator/interpreter. The next step would be for the government to begin recognizing the need for professional translators as civil servants who would be hired on the same basis as other civil servants with the same opportunities for promotion and with the same compensation.

The second step that the government must take is to adjust the official translation rates posted by the Office of Supply to fit the market situation because they serve as a guideline in the semiprivate sector as well. The way that government agencies and translators currently circumvent this hurdle is by agreeing to "adjust" the number of pages so that the final translation fee is more realistic. Even before joining the OECD, most government agencies published various yearly reports and documents, but since it formally joined the international organization, the number of documents has skyrocketed. For example, the Ministry of Defense and the Ministry of Environment each publish a white paper. Considering how these reports are being translated and published, the obvious conclusion is that the matter of translation fees must be resolved quickly.

The importance of the public sector cannot be emphasized enough, especially since these documents represent the government's position on numerous issues. According to a survey of American buyers conducted by the New York branch of the Korean International Trade Association, 15\% of the respondents said that one of the ways to improve trade with Korea is to have better interpretation and translation services (Seoul Economic Daily, November, 20, 1997).

For its part, the private sector should, first, create a new association to pro-actively protect the rights and interests of competent translators by setting a minimum level for translation rates. One of the factors taken into consideration when determining the rates should be the level of difficulty of the text and standardization in calculating rates. For example, if a computer is used to translate, as is often done nowadays, it could automatically calculate the rate. In order to minimize the discrepancy in calculating translation fees, an attempt should be made to standardize to a certain extent. For example, when translating from Korean into English, on average, the length of the text will increase by $120 \%$. The new association must have strict entry qualifications for its members, as well as maintaining a quality control system to ensure the quality of the translations. Based on government recognition of translation as a professional job, for example, Canada's OTIAQ ensures that translators can enjoy certain legal standing.

\section{(ii) Exorbitant Commissions}

Professional translation agencies and other socalled language consulting companies extract exorbitant commissions from the translation fees. In some extreme cases, more than half of the translation fee is considered commission. Even if a client has paid a reasonable price, if the translator receives only a small portion of the translation fee, it is difficult to expect that the final outcome will be satisfactory. For large projects that need a coordi- 
nator, a representative translator can play the role of intermediary to act quickly and efficiently to meet the needs of the client. In other cases, it is important for the translator to meet in person with the client and be compensated accordingly.

In order to resolve the situation, the first priority should be to restructure the translation agency market. Currently there are more than 100 agencies, most of which are small "mom and pop" enterprises established without much capital. These agencies lack an established client base, steady work, a competent translator pool and do mostly rush jobs. To compensate for these disadvantages, the agencies engage in price-dumping, secure "translators" who will work at cheap prices, and deliver unacceptable translations. The clients, unhappy with the end result, look for other agencies while the former agencies have to look for other clients, thereby creating a vicious circle. One of the reasons why these agencies manage to persist is because the overall translation market is expanding.

A complete restructuring of the translation agency market should begin by arranging the agencies according to their area of specialty, and then when some degree of management experience has been accumulated, further mergers can be concluded.

The new association for translators mentioned above is a prerequisite to ensure that the status of professional translators is not threatened by the appearance of these large agencies. The new association and large agencies can create a synergistic effect - the association protecting the status of the translators and the large agencies ensuring that reasonable fees are maintained. This should be accompanied by a continued effort to ensure that cheap, low quality translations are not accepted by the market. The educational institutions, for their part, must ensure stricter control in the selection of future translators.

\section{(iii) Inclusion of Proofreading and Expert} Advice

In advanced countries such as the EU where translation is recognized as a profession, it is strongly recommended that translating be mono-directional, or only into one's mother tongue. However, in the case of Korea where there are very few foreigners who know the Korean language, this is difficult to enforce, and therefore, translating into foreign languages is an accepted risk. In other words, Korean translators must not only work from foreign languages into Korean but also vice versa (as is the case for interpreters). In order to minimize the risks involved, it is imperative for native speakers to proofread the final text before it is delivered to the client.
Proofreading by a native speaker is necessary for two reasons: 1) to ensure that there are no mistakes in the translations, and 2) to check expressions related to nuance, style and communication. Though it is not impossible to find Koreans who have lived most of their lives abroad and have near-native fluency in the foreign language, strictly speaking, they are not native speakers. Proofreading by a native speaker who has the requisite linguistic skills is expected by the clients and understood by the translators. However, as texts become more complicated and technical, there is a growing need to have the translations proofread by native speakers not only for their language but also for their content. This is where the native speaker expert comes in. Sometimes a seemingly innocuous word or passage may take on a completely different meaning in a different field or the translator may not understand the intricacies involved in a given discipline. By having a native speaker expert proofread the text, the translator can rest assured that not only the language but also the content is accurate.

The general conception is that literature translated into foreign languages should be undertaken as a joint effort - with a Korean translator and a native speaker as proofreader - while other non-literary documents even those that are used to introduce Korea to the rest of the world, do not require the same joint collaboration. There are even yearly contests to encourage translation of Korean literary works, that specify that the translation must be a joint effort between a Korean translator and native speaker.

A new and alarming trend in Korea is the growing number of "draft" translators enticed by unscrupulous language institutes and other such profit-seeking agencies. The advertisements bait readers by saying that one can work as a draft translator with a minimum knowledge of a foreign language (high school level), earn lots of money and that some other translator will use the draft to complete the translation. However, just as there cannot be a "draft" poet, a "draft" novelist or a "draft" painter, a translation in itself must be a completed work. All translations must be an end in themselves; hence, only those who can finalize the translation can consider themselves to be translators. The reason "draft" translators have become so popular is that unscrupulous translation institutes are riding on the coattails of the recent boom in certification. It is advertised as a wellpaid, freelance job that a high school graduate can accomplish with the help of a dictionary. However, while linguistic knowledge can be judged and categorized into beginning, intermediate and advanced levels, translation is an act of communication, a complex and continuous process which cannot be 
chopped up into levels. There is no such thing as a certain level of communication - you either communicate or you don't.

One may argue that proofreading is a process similar to draft translating. But the reason for using native speakers to proofread translations is not because they are draft translations but because the translators are not native speakers. The translation is as complete as the competence of the translator allows and the proofreading stage serves to add the finishing touches. A proofreading, thus, is completely different from a "draft" translation. While there are two stages to the draft translations, involving two different translators at each stage, a true translation involves only one translator who is responsible for the final outcome with the help of the proofreader, who is not ultimately held responsible for translation.

Besides proofreading by a native speaker for the language aspects of the translation, experts must be consulted when translating technical material such as scientific/technological, medical and legal documents. The extent of expert consultation in the Korean market is trying to find a translator who majored in the given field in college. In order for the translation market to become more developed, it would be ideal to create a translation group which would be easily accessible to clients. However, the interim step would be to ensure expert consultation on the part of the translators. Without this guarantee, clients will continue to look for experts who know the foreign language or a translator whose spouse is a doctor, lawyer or scientist. Consequently, translators will continue to go unrecognized as specialists.

\section{(iv) Express rates}

There are still many clients in Korea who think that a translator can translate automatically, and they do not take into account the fact that translators work at a certain pace and need time to translate. For example, it is not unusual to take several weeks to write up a report in Korean and have clients set aside only a few days for the translation. In advanced countries, when a job must be expedited, requiring the translator to work at a pace that would not be considered usual, a certain amount of compensation is considered natural. This would cover working during the weekends or over a holiday.

The idea behind the express rate is not to place an added burden on clients but to ensure that they give enough time for the translation to be done properly. This will create an environment for the translator to not only work at a reasonable pace but also to ensure the quality of the translation. The additional $50-100 \%$ fee also acts as a deterrent so that the client does not get into the habit of asking that translations be done quickly.

Another reason why this is necessary is to enhance the status of the translator. For those who consider translation as their main line of work, not merely a hobby they dabble in, it is important that clients understand that there are certain working conditions, just as in any other profession. It should not be considered something that people do in the evening after their regular work in order to earn a little extra money. In Canada, translators are categorized and are recognized by society as professionals just like lawyers and accountants, enabling them to work with pride.

\section{(v) Standardization of translation fees}

Currently, in Korea, no standard has been established in the translation market, except that translations into the " $\mathrm{B}$ " language are slightly more expensive than into Korean and that there are some differences depending on what the " $\mathrm{B}$ " language is. The following three criteria can be used to calculate translation fees: 1) qualifications of the translator; 2) translation volume; and 3) difficulty of the text. There is no agreed upon standard to calculate fees taking into account these three factors.

First, regarding qualifications of the translator, in advanced countries there are reputable translator organizations that set standard rates. They have strict standards for entry and quality control and, when necessary, these organizations negotiate rates with the public sector. Clients can place full confidence in the quality of the translations. Examples of such organizations include ATA in the USA and OTIAQ in Canada. In the case of ATA, in 1963, it established an accreditation committee which studied the standards for accreditation, and it established a detailed set of guidelines which were implemented in 1971. There are more than 1,600 translators who have taken the qualification exams and are accredited by the organization.

As of 1994-1995, OTIAQ has about 1,500 translators and interpreters which have been accredited by the association. OTIAQ categorizes its membership into honorary members, accredited members and student members. Honorary members are those who consider translation to be their profession and who have contributed to the development of the association; accredited members are those members who enjoy the full rights of the association; and student members are those studying in the field. Student members must belong to the association for five years and must prove their translation ability in preparation for being recognized by the association. For five long years, the student members must dedicate themselves to translation in order to gain the title of accredited 
OTIAQ translator. This is how OTIAQ keeps strict tabs on its membership.

There is no official body in Korea that compares with these two associations. The Korea Translators Association was formed in 1971 and it is a member of FIT, but for several reasons, it does not have the reputation or status that it should. First, even though the association promotes itself as the Korean representative of FIT which cooperates with UNESCO, there are no cooperative ties between the association and UNESCO. The Korean Committee of UNESCO has even gone so far as to demand that it discontinue using its name in its advertisements or insinuating that there are any official relations between the two associations.

Second, despite the fact that it purports to defend the rights of translators in Korea, it does not have any ties with the major institutions which teach translation. In 1979, GSIT was the first institution of its kind to be established in Korea, and yet during the past twenty years there have been no ties, alliances, agreements or any other links whatsoever.

Third, since 1994 the association has been conducting translation certification exams which have met with a great deal of controversy. Although initially it seemed to be a success, with almost 10,000 candidates applying for the exams, the lack of transparency in evaluating the answer sheets, management of those who passed the test and ethical questions regarding texts used at the institutes to prepare for the exam made the association the target of criticism in the media.

For these reasons, the Korea Translators Association has not been in a position to set a standard for translation fees, and some even say that it is simply one of many groups or agencies which mediate translation work.

Another reason why it is difficult to set standards for translation fees has to do with calculating the final output. Traditionally in Korea when all texts were handwritten, a grid was used to calculate the original and the same method of counting the number of grid sheets was used for translations as well. As in the rest of the world, today computers are more commonly used by translators (and demanded by the client) and when the translation fee is calculated according to the number of grid sheets, the computer can automatically calculate the final number. However, the trend towards using computer pages is unmistakable. The standard used in Korea is 25 lines (A4) with a 12 font size.

Regardless of which method is used, there are still two ways to calculate fees. The first is according to the source language. For example, if an English text is translated into Korean, the length or number of words which appear in the source text is used to calculate the fee. Clients tend to prefer this method because they feel that it is difficult to estimate and set a budget for the final output since there can be a discrepancy depending on the translator. However these concerns can be dispelled by establishing a general rule of thumb depending on the target language. For example when an English text is translated into French, it is generally understood that the French text will be about $130 \%$ longer. Translators tend to dislike this calculation method because there is not a uniform standard in the source text.

The other method is to calculate according to the target language, in other words, the number of pages or words of the output. This method is preferred by translators because they can translate without restrictions. In most cases, translations tend to be slightly longer than the original text and translators do not like to feel unnaturally restricted. In the case of Korean into Russian, for example, the final output can be $150-200 \%$ longer than the original.

The final reason that it is difficult to standardize translation fees has to do with the difficulty of the text. It is generally accepted in Korea that advertisement copy, legal documents, expert scientific and technical documents, as well as economic and business documents and art critiques are more difficult than run-of-the-mill texts. However, depending on the expertise, experience and disposition of the translator, a text can be considered difficult or easy.

\section{The Market of Salaried Translators}

Salaried translators are those who join a company or organization and work exclusively as translators. Though there are salaried translators in government agencies, their numbers are minimal and will therefore not be included in this paper. Most salaried translators must pass an entrance test and have their qualifications accredited before being employed. Salaried translators can be divided into those who work full-time for their clients at their place of work and those who work as in-house translators for translating agencies. In both cases, the majority consist of those who have studied a foreign language in college and have relatively little experience translating. Despite these handicaps, since most of the work is repetitive and routine translating similar administrative documents, these translators very quickly accumulate the "translating" skill needed or must quit their jobs.

In-house translators are needed when there is a constant demand for translation or when a special need arises for a certain project. In both cases, in-house translators are almost always hired on a contractual basis, usually on a yearly contract. Salaries fluctuate depending on the size of the 
company, the translator's educational background and training. A graduate of a graduate school of interpretation and translation can command an initial yearly salary of about US $\$ 25,000$ which is more than the salary of a middle level manager of a big conglomerate in Korea. In most cases, they must be able to produce quality translations in both directions and are responsible for material that will be distributed abroad. For large translation projects that are too big to be handled by one translator, outsourcing is an option with the inhouse translator coordinating the translation project. The salaried translator acts as team leader and troubleshooter, ensuring that terminology is accurate and uniform, that style is in accordance with the other documents of the company or the relevant organization involved, and that the final output is consistent overall. The salaried translator is in a unique position to act as bridge between the translators and the organization.

One of the disadvantages that the salaried translator faces, is that no matter how well the employer might have predicted his workload, there are bound to be fluctuations - at times, the translator will be overwhelmed with work and at others he will be idle. When the work eases up, it is important that the translator use the time to read related literature or documents that will help with future translations. For his or her part, the employer should also understand that the translator is not "goofing off." Giving them busy-work does not benefit the professional growth of translators.

One point of interest is that following the economic crisis that impacted all of Asia in the end of 1997, there was some concern that the interpretation and translation market would be adversely affected. Quite to the contrary, demand rose because of the stream of M\&A's and corporate restructuring which were conducted with the help of foreign consulting firms. Thanks to this rise in demand, interest in and popularity of the field of interpretation and translation has risen because college students have realized that there will always be a demand for competent interpreters and translators.

In the case of in-house translators working for professional translation agencies, they are, for the most part, constantly overwhelmed with work. They have to work double-duty as translators and proofreaders of translations which have been outsourced. For these reasons, the turnover rate is said to be very high. Since most of these agencies are small and not very well financed, salaries are relatively low and the translators are usually unhappy with their position because there is little time for them to continue to hone their skills. While the internationally-accepted daily workload is 10-12 pages into one's mother tongue, in-house translators at such agencies are expected to work at double, and sometime even, triple the average speed. Another factor is that they are often burdened with "draft" translations which they have to review and correct. This is in sharp contrast to the coordinating that in-house translators of companies do because, as was mentioned above, it consists of organizing the final translation and not of reviewing semi-finished material.

Freelance translators can also act as coordinators. In such cases, experienced translators acting as coordinators are charged of forming a team of translators and are responsible for the final outcome. If the coordination fee has not been included in the original estimate, the translators themselves must agree to give a certain percentage to the coordinator, but they consider this to be like a commission given to translation agencies, and therefore tend to dislike being part of a translation team. However, with the increase in the number of projects which require a vast amount of material to be translated quickly, it is important for translators to adjust to the changing market situation.

\section{THE KOREAN TRANSLATION MARKET AS CATEGORIZED BY TEXT \\ 1. Technical Texts}

When talking about translation, most Koreans think of literary translations because they have read many translations of foreign literary masterpieces. There have also been many efforts to translate Korean literature into foreign languages including contests with substantial monetary prizes and the designation of 1996 as the year of literature. However as international exchanges become more diversified, the proportion of translated literary works pales in comparison with scholarly works, government documents, company documents, and brochures. There are others, such as non-scholarly and non-literary books, various data, movies, magazines, and cartoons, and the list goes on. In 1996, the number of published books reached 4,834 , of which only $25 \%$ or 1,132 books can be categorized as literature. The remaining $75 \%$ were non-literary works. This is true for published works which are aimed at the general public. For non-published material that is targeted to a limited audience, it can be said that almost all of the material consists of technical texts which can be categorized as general, economic, legal, scientific and technological. The general area encompasses international affairs, social and literary works; economics, business, management, trade and finance; legal texts, contracts/regulations, public documents; science, technology, medicine, equipment/ system manuals.

Currently, translation agencies are most ac- 
tive in the technical text market. There are now 10 translation agencies that are registered as corporate bodies and another 100 small translation agencies (Chosun Daily, Jan. 31, 1994). According to the Internet home page of Florence Co. Ltd., a representative translation agency, the turnover of this company in 1996 was 4.2 billion won; the company specializes in manuals and computer programs. The fact that about 80 full-time inhouse translators are employed by a single translation agency reflects the size of the translation market in Korea.

The technical text translation market is mainly characterized by relatively strict quality-control. Since professional translation agencies lead the market and most of their clients are companies, the companies must be satisfied with the end-result. Unlike textbooks or other translations where the target audience is undefined, clients of technical texts are dealing with material that they know well and they will let the translator know immediately if the output is unsatisfactory.

On the surface, it appears as if translation fees for technical texts are at the high-end of the spectrum. However, a closer look reveals that while the translation agencies receive the full amount from their clients, the amount that the translator actually receives is either the same or at times even less than that which translators receive for more general material.

\section{AUDIOVISUAL MATERIAL}

Translation of audiovisual material first began in the 1960s when public television started to broadcast foreign films. Since then, the market has expanded at a rapid pace, and includes not only foreign films for TV, but also movies, videos, animated films, documentaries, in-house training films, product advertising and corporate public relations films. With the recent introduction of cable $\mathrm{TV}$, the market has expanded even further. An interesting turn of events is that Korean movies are gradually being introduced to the international market and so the demand for translations into foreign languages is rising.

There are no accurate statistics regarding the size of the audiovisual translation market in Korea, but according to a Korean daily (Kyunghyang Daily, Sep. 24, 1996), there are about one thousand audiovisual translators of whom more than $70 \%$ are female, and during the past 2-3 years, young translators in their twenties have joined the market.

In most cases, audiovisual translators find work through acquaintances at TV stations or film productions companies. TV stations and private language institutes have also started courses to teach audiovisual translators, and this has met with great success. The reason for their popularity is not so much that translator-trainees hope to learn translating skills, but that they hope to make connections through these courses. The translatortrainees pay almost US $\$ 2,000$ for a 3 to 6 -month course and there is some question as to how much they learn. In fact, experts say that they would do better to find a reputable audiovisual translation agency and work as apprentices in order to gain experience.

Some side-effects the mass production of audiovisual translators are slowly emerging. The biggest problem is that the translators do not understand the culture and therefore end up depending on the script, which results in mistranslations.

Though the process of translating from and into Korean is the same as for translations of published works, the difference in audiovisual translating is that the translator is limited by the number of letters and words. Experts agree that it takes a minimum of ten years to reach a certain level and at least five years to be able to competently translate a movie. Though it is said that there are about one thousand audiovisual translators, a handful of translators monopolize the market for movies released in theaters and television.

The translation fees for audiovisual material fluctuate dramatically, but the average for a movie released in a movie theater is about US\$400-600, videos about US\$100-200 and TV movies about US $\$ 80$ per 10 minutes. However, depending on the experience and reputation of the translator, content and time spent, translation fees can vary enormously.

\section{CONCLUSION}

Though great strides have been made in elevating the status of translators, the increasing size of the translation market has led to numerous untrained translators being hired to do work that requires a professional translator. The KSCI, which maintains strict quality controls on translations, is the market leader, but there are many profit-hungry agencies that undermine the work of the KSCI by undercutting prices and demanding exorbitant commissions. A reorganization of the translation market is in order, and this would entail regrouping translation agencies by specialty. This is a prerequisite for improving both the status of translators and the compensation they receive.

In order to ensure that the quality of translations improves, graduate schools of interpretation and translation must select only the most qualified students, while agencies must give work only to those qualified, ensuring that the translations have been proofread by an expert. "Draft translations," which are an abomination, should be regulated 
and language institutes should not be allowed to rely on this practice.

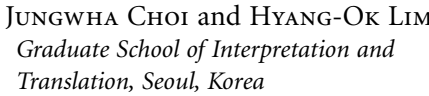

\section{REFERENCES}

A. The following newspaper articles were used to study the Korean market:

1) Chosun Daily, January 31, 1994

2) Chosun Daily, December 17, 1997

3) Hankuk Ilbo, June 9, 1995

4) Kyunghyang Daily, September 24, 1996

5) Kyunghyang Daily, February 17, 1997

6) Seoul Economic Daily, November 20 , 1997

B. The following books were referred to for theory:

Сног, J. (1989): The Practice of Interpretation, Seoul, Shillon.

- (1993): To Interpret and Translate the Right Way, Seoul, Shillon.

- (1998): Introduction to Interpretation and Translation, Seoul, Shillon.
Seleskovitch, D. and M. Lederer (1995): A Systematic Approach to Teaching Interpretation, Luxembourg, European Communities.

- (1986): Interpréter pour traduire, Paris, Didier Érudition.

C. The following material was used to study the translation market and status of translators:

1) American Translators Association (ATA)

2) Career Opportunities in the European Commission - Translation Service, EU

3) National Accreditation Authority for Translators and Interpreters, Australia

4) L'Office des professions du Québec

5) Official Journal of the European Communities (vol. 39)

6) Qu'est-ce que l'OTIAQ?

7) Recommendation on the Legal Protection of Translators and Translations and the Practical Means to Improve the Status of Translators. Statut du traducteur Bulletin d'information de l'Association des anciens élèves de l'ESIT ( $\left.\mathrm{n}^{\circ} 2\right)$

The translator's charter - FIT (International Federation of Translators) 